University of Nebraska - Lincoln

DigitalCommons@University of Nebraska - Lincoln

Faculty Publications from the Harold W. Manter Laboratory of Parasitology

$12-1982$

\title{
Haliotrema (Monogenea: Ancyrocephalinae) from Ostraciid Fishes in Guadeloupe, West Indies
}

Jean Claude Vala

Faculte des Sciences

Claude Maillard

U.S.T.L.

Robin M. Overstreet

Gulf Coast Research Laboratory, robin.overstreet@usm.edu

Follow this and additional works at: https://digitalcommons.unl.edu/parasitologyfacpubs

Part of the Parasitology Commons

Vala, Jean Claude; Maillard, Claude; and Overstreet, Robin M., "Haliotrema (Monogenea:

Ancyrocephalinae) from Ostraciid Fishes in Guadeloupe, West Indies" (1982). Faculty Publications from the Harold W. Manter Laboratory of Parasitology. 466.

https://digitalcommons.unl.edu/parasitologyfacpubs/466

This Article is brought to you for free and open access by the Parasitology, Harold W. Manter Laboratory of at DigitalCommons@University of Nebraska - Lincoln. It has been accepted for inclusion in Faculty Publications from the Harold W. Manter Laboratory of Parasitology by an authorized administrator of DigitalCommons@University of Nebraska - Lincoln. 


\title{
HALIOTREMA (MONOGENEA: ANCYROCEPHALINAE) FROM OSTRACIID FISHES IN GUADELOUPE, WEST INDIES
}

\author{
Jean Claude Vala, ${ }^{*}$ Claude Maillard, $\dagger$ and Robin M. Overstreetł \\ ABSTRACT: Six sympatric species of Haliotrema Johnston and Tiegs, 1922 are described from ostraciid fishes \\ in Guadeloupe, West Indies. All have a basic cone-shaped cirrus, but characteristics of that and other terminal \\ genitalia plus those of anchors can differentiate them: H. guadeloupensis sp. n. from Lactophrys triqueter (type- \\ host) and L. bicaudalis; $H$. torridum sp. $\mathrm{n}$. from $L$. triqueter (type-host) and Acanthostracion polygonius; $H$. \\ glandulosum sp. n. from $L$. triqueter (type-host) and $L$. bicaudalis; $H$. minutum sp. n. from A. polygonius; $H$. \\ lactophrys (MacCallum, 1915) comb. n. from A. polygonius and A. quadricornis which is transferred from the \\ genus Ancyrocephalus Creplin, 1839; and $H$. kritskyi nom. nov. from $A$. polygonius. The latter has been given \\ a replacement name for Parahaliotrema brevis Mizelle and Kritsky, 1969 which would become a junior homonym \\ because it, H. affinis (Mizelle and Kritsky, 1969) comb. n., H. cornutus (M. and K.) comb. n., H. grandis (M. \\ and K.) comb. n., H. pacificus (M. and K.) comb. n., and H. zebrasoma (M. and K.) comb. n. are all transferred \\ from the genus Parahaliotrema Mizelle and Price, 1964. We follow others in considering that genus to be a \\ junior synonym of Haliotrema. We also determined that at least Ancyrocephalus parupenei Yamaguti, 1968 and \\ A. pauu Yamaguti, 1968 do not belong in Ancyrocephalus. However, investigation of $H$. australe Johnston and \\ Tiegs, 1922 and other species should precede transferring those species to another genus.
}

A complex of six sympatric species of the ancyrocephaline Haliotrema Johnston and Tiegs, 1922 infested boxfishes (Ostraciidae) from Guadeloupe. Infestations with four of these monogeneans occurred on two or three different related host species; such occurrence on the same host is unusual for most monogeneans (Lebedev, 1978). This paper describes all six of those species, four of which are new.

\section{MATERIALS AND METHODS}

Living specimens were collected from fishes caught by trap net up to $4 \mathrm{hr}$ prior to examination. Some were studied alive and others fixed in $70 \%$ ethyl alcohol. The latter were stained using borax carmine or light green, and sclerified structures were examined in Berlese's chloral-gum solution. Measurements are in micrometers $(\mu \mathrm{m})$. Representative specimens have been deposited in The Museum National d'Histoire Naturelle de Paris (MNHNP). Because the different species have several characters in common, the first is described in detail and the remainder are characterized primarily by their diagnostic features. Some features such as two primary collecting ducts from prostatic glands may occur on all species, but necessitate living material or special techniques and were not discerned for all species. Terms defining parts of the hamulus vary and overlap among authors. We treat the structure as a dagger with shaft (handle) and curved blade, separated by a knoblike

Received 13 August 1981; revised 19 October 1981; accepted 13 December 1981.

* Faculté des Sciences, 33 Rue Louis Pasteur, 84000 Avignon, France.

† U.S.T.L., Place E, Bataillon, 34060 Montpellier Cedex, France.

‡ Gulf Coast Research Laboratory, Ocean Springs, Mississippi 39564. guard. Unfortunately, the guard in some species protrudes more than the shaft. Identification of fishes conforms with Randall (1968).

\section{Haliotrema guadeloupensis sp. $\mathbf{n}$. (Figs. 1-6)}

\section{Description}

Based on 18 whole mounts and 12 living specimens. Body 620 to 780 long by 150 to 180 wide. Cephalic margin indented slightly laterally, anterior end with five to seven cephalic glands emptying into three bundles of ducts on each side. Eyespots two pair, dorsal; posterior pair usually larger and farther apart than anterior pair. Haptor conspicuously set off from body, 75 long, up to 200 wide, widest at middle. Marginal hooklets ribbed, similar in shape, symmetrical in dextral and sinistral fields, 14 in number, 9 to 11 long. Ventral transverse bar bulky, arcuate, with two divergent processes at each end, with specific measurements (see key to lettering in Fig. 2): $x=80$ to $90, w=15$ to 18 ; anterior process longer than wide, 8 long, nearly hemispherical, pointing anterolateral; posterolateral process narrower and more tapered than anterior process, 15 to 18 long. Ventral hamuli bulky with wide base; blade with recurved point, with specific measurements (see key to lettering in Fig. 3): $a=33$ to $42, b=33$ to 37 , $c=5$ to $7, d=8$ to $12, e=14$ to 15 . Dorsal transverse bar narrowest near center, with specific measurements (key to lettering same as in Fig. 2): $x=65$ to 75 , $w=$ 7 to 8 ; outermost process directed anterolateral; inner process short and bilobed, at anterointernal base of lateral process and directed similarly to it. Dorsal hamuli with specific measurements (key to lettering same as in Fig. 3): $a=33$ to $35, b=32$ to $33, c=6$ to $7, d=$ 10 to $15, \mathrm{e}=11$ to 13 .

Mouth ventral. Pharynx nearly spherical, 40 to 50 in diameter, with anterior margin at level of posterior pair of eyespots. Ceca uniting posteriorly.

Testis smooth, intercecal at posterior extension, 120 to 140 long by 100 to 120 wide. Vas deferens sinistral, sinuous, looped around left cecal branch; distal portion swollen as seminal vesicle, directed posteriorly, with 

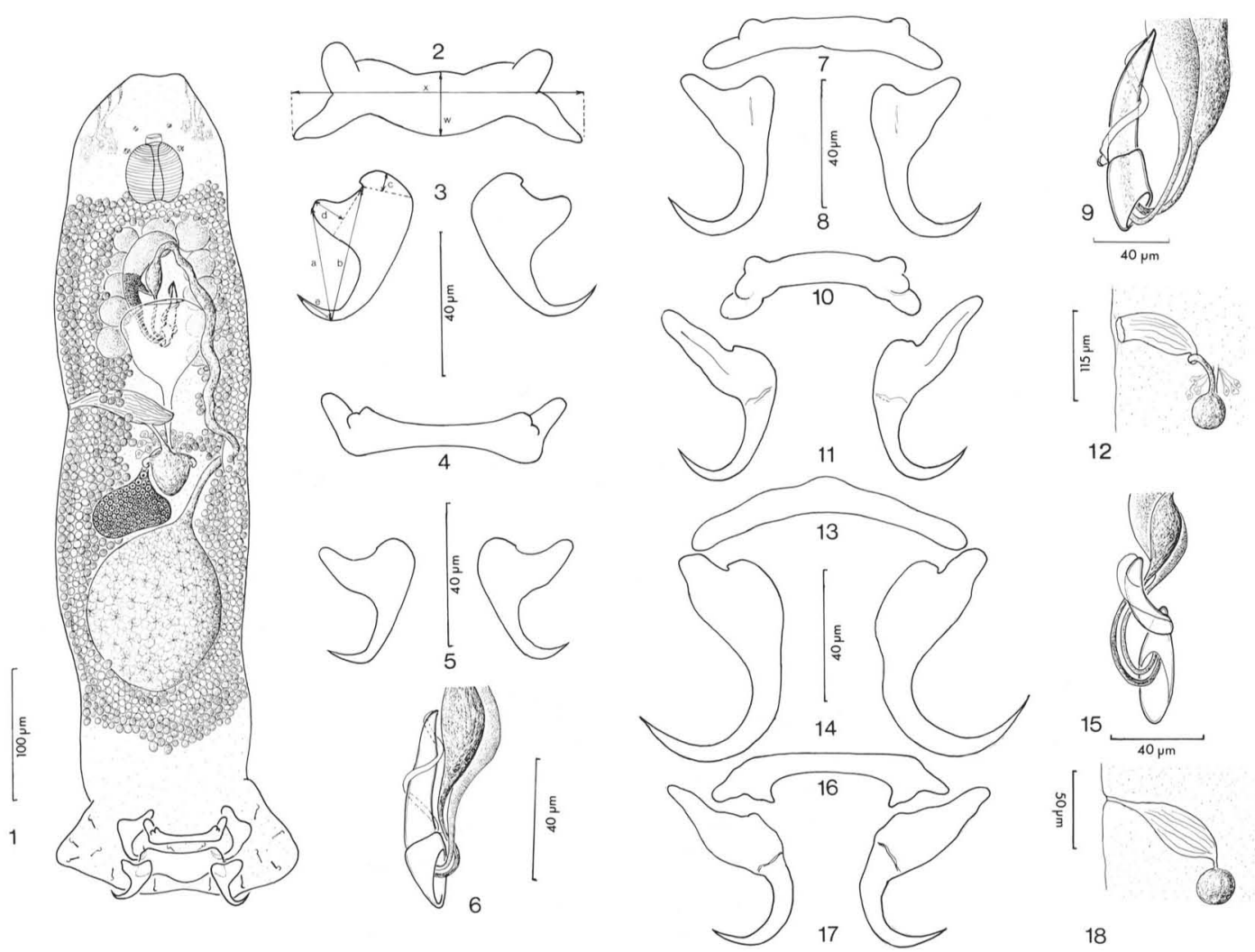

FIGURES 1-18. 1-6. Haliotrema guadeloupensis sp. n. 1. Entire worm, ventral view. 2. Ventral bar. 3. Ventral hamuli. 4. Dorsal bar. 5. Dorsal hamuli. 6. Cirrus. 7-12. Haliotrema lactophrys (MacCallum, 1915) comb. $\mathrm{n}$. 7. Ventral bar. 8. Ventral hamuli. 9. Cirrus. 10. Dorsal bar. 11. Dorsal hamuli. 12. Vagina. 13-18. Haliotrema kritskyi nom. nov. 13. Ventral bar. 14. Ventral hamuli. 15. Cirrus. 16. Dorsal bar. 17. Dorsal hamuli. 18. Vagina.

narrow duct entering into base of cirrus. Cirrus bipartite, shaped like slightly curved horn, 58 to 70 long; basal portion with beveled opening running parallel with longitudinal axis of body, 28 to 30 long; distal portion directed anteriorly, progressively decreasing in diameter, 33 to 40 long, with short accessory sclerotized vane making one complete spiral along entire length. Prostatic reservoir dextral, 68 long, larger than and arched around seminal vesicle, opening by narrow duct to base of cirrus. Prostatic glands relatively large and nearly spherical, dorsal, 11 to 12 in number, entering into reservoir by two primary collecting ducts; ducts entering vesicle at anterior and at center.

Ovary dextral, near anterior testicular border, slightly irregular in shape, 40 to 50 long by 50 to 70 wide. Vagina 90 long by 18 wide, with length $50 \%$ of body width, opening externally 30 to $40 \%$ of body length from anterior end at right margin, with longitudinal striae lining slightly sclerified walls, 95 to 110 long by 18 to 20 at widest portion, extending beyond median longitudinal axis of body. Seminal receptacle approximately medial, at or near left anterolateral margin of ovary, with pair of corkscrewlike extensions laterally, surrounded anteriorly by pronounced Mehlis' gland, with sclerified vaginal duct entering vagina near proximal $1 / 4$ to $1 / 3$ of structure on posterior face. Uterus approximately tetrahedral in shape anteriorly, opening ventrally at level of cirrus. Vitelline glands surrounding ceca. Eggs not observed.

Hosts: Lactophrys triqueter (Linnaeus) (type-host) and L. bicaudalis (Linnaeus).

Site: Gills.

Localities: Sainte Anne (type-locality) and Bananier, Guadeloupe.

Specimens deposited: Holotype MNHNP No. TJ 57, paratype No. TJ 58.

Etymology: The specific name refers to the typelocality.

\section{Remarks}

Several species of Haliotrema have been described as having a cirrus of similar structure to $H$. guadeloupensis and to the other species described later in this paper: $H$. australe Johnston and Tiegs, 1922; H. allornata Paperna, 1972; H. caballeroi Euzet and Vala, 1976; H. carai- 
bensis Euzet and Vala, 1976; H. chrysostomi Young, 1968; $H$. dascyllusi Paperna, 1972; $H$. epinepheli Young, 1968; H. macassariensis Yamaguti, 1963; Parahaliotrema cornutus Mizelle and Kritsky, 1969; $P$. pacificus Mizelle and Kritsky, 1969; and P. brevis Mizelle and Kritsky, 1969. The nomenclature of the last three species will be treated later in this paper. All the species can be distinguished from $H$. guadeloupensis by having differently-shaped hamuli and transverse bars on the haptor. Only two ancyrocephalines have been described from members of the Ostraciidae. The first, previously known as Ancyrocephalus lactophrys (MacCallum, 1915), has a longer cirrus (105-115 vs. 58-70 $\mu \mathrm{m})$ and will be treated next in this paper. The second, described as $P$. brevis, differs by having a cirrus with a distal twisted portion and a V-shaped ventral transverse bar. It will be treated after $A$. lactophrys.

Haliotrema lactophrys (MacCallum, 1915) comb. $n$. (Figs. 7-12)

Diplectanum lactophrys MacCallum, 1915.

Ancyrocephalus lactophrys: Johnston and Tiegs, 1922.

\section{Supplemental data}

Based on 18 whole mounts and eight living specimens. Body 440 to 1,250 long by 120 to 260 wide. Cephalic glands present. Eyespots numbering two pair. Haptor with 14 marginal hooklets. Ventral transverse bar slightly curved, with anterior process wider than long, with measurements: $x=60$ to $83, w=8$ to 10 . Ventral hamuli with upturned guard, with measurements: $\mathrm{a}=52$ to $58, \mathrm{~b}=45$ to $50, \mathrm{c}=6$ to $8, \mathrm{~d}=10$ to $12, \mathrm{e}=22$ to 25 . Dorsal transverse bar slightly curved, with lateralmost process directed posterolateral, with small single anterolateral bulges, with measurements: $\mathrm{x}=65$ to $80, \mathrm{w}=8$. Dorsal hamuli with thick welldeveloped guard on outer edge, with fracture between base and blade, with measurements: $a=62$ to $70, b=$ 45 to $48, \mathrm{c}=5, \mathrm{~d}=25$ to $29, \mathrm{e}=22$ to 25 . Ceca united posteriorly. Testis intercecal, subspherical. Vas deferens looped around left cecal branch. Seminal vesicle present. Cirrus conical, slightly curved, bipartite, 105 to 115 long; basal portion with beveled opening 40 long oblique to body axis; distal portion with sclerotized vane making single spiral along entire length Prostatic reservoir 86 long. Prostatic glands subspherical, of uncertain number probably from 15 to 20 , with two primary collecting ducts; ducts entering reservoir at anterior and center. Seminal receptacle nearly spherical, without anterior lateral projections. Vagina 113 long by 37 wide, with length $51 \%$ of body width, with longitudinal striae lining slightly sclerified walls, opening at right margin, with vaginal duct attached proximally.

Hosts: Acanthostracion polygonius Poey and $A$. quadricornis (Linnaeus) (type-host $A$. quadricornis, listed as Lactophrys tricornis by MacCallum, 1915).

Site: Gills.
Locality: Sainte Anne, Guadeloupe; Campeche, Mexico $\left(19^{\circ} 15^{\prime} 05^{\prime \prime} \mathrm{N}, 90^{\circ} 34^{\prime} 45^{\prime \prime} \mathrm{W}\right)$

Specimens deposited: MNHNP No. TJ 54-55.

\section{Remarks}

Our examination of nine cotypes of Diplectanum lactophrys MacCallum, 1915 (USNM Helm. Coll. No. 35692) collected from the New York Aquarium revealed them to be conspecific with our described specimens from Guadeloupe and additional formalin-fixed specimens from Mexico. The ceca united posteriorly and the vas deferens looped around the left cecal branch, showing that the species belongs in the genus Haliotrema. Neither of these characteristics was pointed out by MacCallum (1915) or by Price (1937), who also used the cotypes for a redescription. Hargis (1955) examined 42 specimens identified as Ancyrocephalus lactophrys from "Lactophrys tricornis" in Alligator Harbor, Florida. He did not mention the ceca or vas deferens, said the haptoral bars varied in shape, and recognized a need to redescribe the species. The relative consistency in haptoral bars in our specimens plus the presence of sympatric species on some ostraciids suggest that Hargis may have been dealing with more than one species.

Haliotrema kritskyi nom. nov. (Figs. 13-18)

Parahaliotrema brevis Mizelle and Kritsky, 1969.

\section{Supplemental data}

Based on three fixed and four living specimens. Body 610 to 680 long by 160 to 180 wide. Eyespots numbering two pair. Haptor pentagonal, with 14 marginal hooklets, 140 to 180 long by 50 to 60 wide. Ventral transverse bar not bulky, slightly arched, processes not distinct, with measurements: $x=74$ to $83, w=12$ to 14. Ventral hamuli with flat base and upturned guard, having slight notch separating shaft and guard, with measurements: $\mathrm{a}=55$ to $62, \mathrm{~b}=51$ to $55, \mathrm{c}=2, \mathrm{~d}=$ 8 to $11, \mathrm{e}=25$. Dorsal transverse bar with roughly angular processes 8 to 10 long both directed posteromedial, with measurements: $x=72$ to $80, w=8$ to 10 . Dorsal hamuli with fracture between base and blade, smaller than ventral hamuli; with measurements: $a=$ 52 to $55, \mathrm{~b}=35$ to $37, \mathrm{c}=$ nearly rounded off, $\mathrm{d}=22$ to $28, \mathrm{e}=15$ to 18 . Pharynx 45 long by 30 wide. Ceca united posteriorly. Testis intercecal, globular, approximately 80 long by 110 wide. Vas deferens looped around left cecal branch. Seminal vesicle spindleshaped. Prostatic reservoir 100 long. Prostatic glands subspherical, of uncertain number probably from 15 to 20 . Cirrus bipartite, 72 long; basal opening parallel to longitudinal body axis; distal portion twisted with deep sclerotized vane making about $1 / 2$ spiral. Ovary pretesticular, approximately 50 to 55 . Vagina pyriform, with longitudinal striae lining slightly sclerified walls, 77 to 84 long by 24 wide, with length $43 \%$ of 
body width, opening on right side of body. Eggs tetrahedral-shaped, 58 along side, with filament extending from single pole 150 long.

Host: Acanthostracion polygonius Poey. Site: Gills.

Locality: Sainte Anne, Guadeloupe.

Specimen deposited: MNHNP No. TJ 56.

Etymology: The specific replacement name honors Delane C. Kritsky of Idaho State University.

\section{Remarks}

We tentatively identify our specimens as Parahaliotrema brevis Mizelle and Kritsky, 1969, originally described from Acanthostracion quadricornis in Florida. Mizelle and Kritsky (1969) described the haptoral bars as somewhat variable in shape. The slight difference between those and the shape of bars in our material plus slight differences between the two descriptions in shape of haptor, size of ventral anchors, and possibly shape of cirrus may be attributed to preparation, biological variation, age, or host. We interpret what Mizelle and Kritsky (1969) called dual anchor filaments on anchors as sides of the sheath, or domus, in which the hamulus slides, and not as a diagnostic feature. Those authors did not observe the seminal receptacle or prostate in their specimens as we did on ours. Until significant differences can be used to distinguish these two populations as separate species, we prefer to treat them as conspecific.

However, Parahaliotrema brevis needs to be transferred to the genus Haliotrema, and this action creates a homonym. Young (1968: 70) transferred Pseudohaliotrema brevis Mizelle and Price, 1964 from Zanclus cornutus (as Z. canescens) to the genus Haliotrema, even though he could not positively confirm whether or not the vas deferens in that species looped around the left cecum. In the same paper, he transferred the type-species of Parahaliotrema Mizelle and Price, 1964, P. parahaliotrema Mizelle and Price, 1964, which is also from $Z$. cornutus, to Haliotrema. Those actions seem especially justified to us because Yamaguti (1968) erected five new species of ancyrocephalines from acanthurids (three from $Z$. cornutus) in Hawaii that he (1968: 94) acknowledged in a footnote could be conspecific with species from $Z$. cornutus described by Mizelle and Price (1964). Yamaguti's monograph was completed before the paper by Mizelle and Price was published. Haliotrema canescens Yamaguti, 1968 and $H$. angulare Yamaguti, 1968, presumed junior synonyms of Parahaliotrema parahaliotrema and Pseudohaliotrema brevis, respectively, both had their vas deferens looping around the left cecum. Mizelle and Kritsky (1969), unaware of the nearly concurrent paper by Young, erected six new species of Parahaliotrema. All of those are herein transferred to Haliotrema, at least until Haliotrema is properly reviewed, as $H$. affinis (Mizelle and Kritsky, 1969) comb. n., H. cornutus (Mizelle and Kritsky, 1969) comb. n., $H$. grandis (Mizelle and Kritsky, 1969) comb. n., H. pacificus (Mizelle and Kritsky, 1969) comb. n., and H. zebrasoma (Mizelle and Kritsky, 1969) comb. n. The sixth, P. brevis from the ostraciid Acanthostracion quadricornis, clearly has the vas deferens looping around the left cecum. Because the name in the new combination would become a junior homonym of $H$. brevis (Mizelle and Price, 1964), a replacement name for the preoccupied one for the species from the ostraciid is in order. When we notified Delane C. Kritsky (personal communication) about the proposed homonym, he requested that we, rather than he, should establish a replacement name. Thus, we name the species $H$. kritskyi nomen novum in his honor.

\section{Haliotrema torridum sp. $\mathbf{n}$.} (Figs. 19-24)

\section{Description}

Based on five whole mounts and seven living specimens. Body 580 to 670 long by 160 to 260 wide Eyespots numbering two pair. Haptor with 14 marginal hooklets. Ventral transverse bar not bulky, nearly flat on anterior margin, with anterior process not prominent but distinguished from long nearly lateral one by a notch, with measurements: $x=63$ to $75, w=7$ to 8 . Ventral hamuli with short rounded shaft, with short blade, with measurements: $a=35$ to $46, b=35$ to 38 , $\mathrm{c}=2$ to $3, \mathrm{~d}=12$ to $15, \mathrm{e}=19$ to 23 . Dorsal transverse bar U-shaped, with slight indentation along midposterior border, without distinct processes, with measurements: $x=67$ to $75, w=8$ to 9 . Dorsal hamuli with broader and bulkier base than ventral hamuli, with measurements: $a=35$ to $40, b=29$ to $37, c=2$ to $3, \mathrm{~d}=10$ to 12 . Cirrus indistinctly bipartite, 58 to 65 long; basal portion 25 long by 13 wide, with relatively thick wall; distal portion conical, bent, with short sclerotized vane making single spiral along entire length, 30 long. Prostatic reservoir 83 long. Prostatic glands subspherical, of uncertain number probably from 15 to 20 . Vagina 76 to 84 long by 23 wide, with length about $40 \%$ of body width, dextral, slightly sclerified with longitudinal striae on wall, with wide aperture. Seminal receptacle spherical, with two small anterior lateral extensions visible in living specimens, with vaginal duct entering near proximal $1 / 3$ of vagina on anterior face.

Hosts: Lactophrys triqueter (Linnaeus) (type-host) and Acanthostracion polygonius Poey.

Site: Gills. 


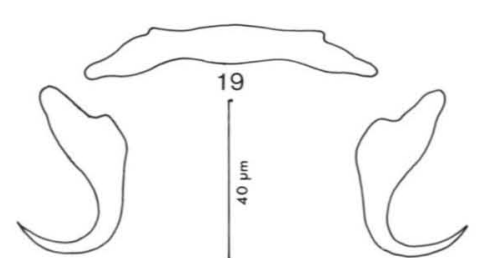

20
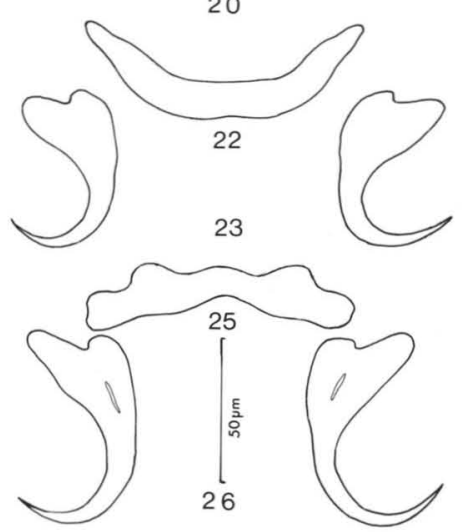

26
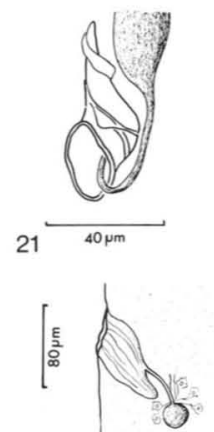

24

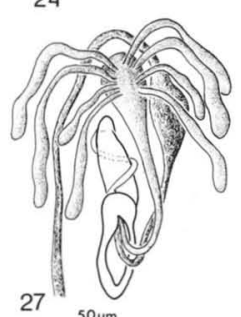

$50 \mu \mathrm{m}$
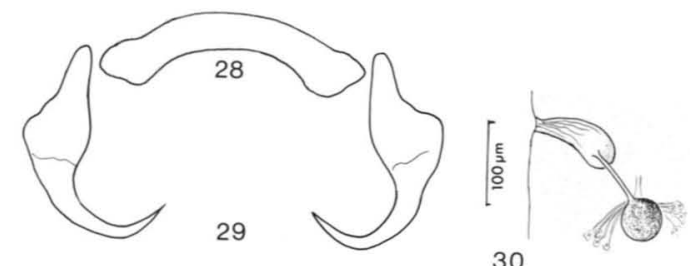

30

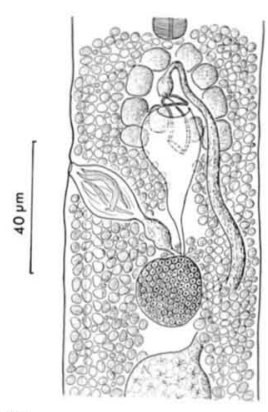

31
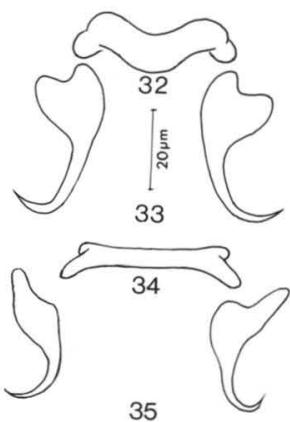

Figures 19-35. 19-24. Haliotrema torridum sp. n. 19. Ventral bar. 20. Ventral hamuli. 21. Cirrus. 22. Dorsal bar. 23. Dorsal hamuli. 24. Vagina. 25-30. Haliotrema glandulosum sp. n. 25. Ventral bar. 26. Ventral hamuli. 27. Cirrus. 28. Dorsal bar. 29. Dorsal hamuli. 30. Vagina. 31-35. Haliotrema minutum sp. n. 31. Detail of the genital anatomy. 32. Ventral bar. 33. Ventral hamuli. 34. Dorsal bar. 35. Dorsal hamuli.

Localities: Sainte Anne (type-locality) and Sainte Rose, Guadeloupe.

Specimens deposited: Holotype, MNHNP No. TJ 52, paratype No. TJ 53.

Etymology: The Latin torridum refers to the tropical type-locality.

\section{Remarks}

The shape of both the indistinctly bipartite cirrus and haptorial structures can be used to diagnose $H$. torridum; however, the presumed unique attachment of the vaginal duct to the anterior surface of the vagina serves as a primary diagnostic feature.

\section{Haliotrema glandulosum sp. $\mathbf{n}$.} (Figs. 25-30)

\section{Description}

Based on three fixed and nine living specimens. Body 1,190 to 1,310 long by 330 to 360 wide. Eyespots numbering two pair. Haptor with 14 marginal hooklets. Ventral transverse bar arcuate, with hemispherical bulges directed anterolateral, with measurements: $\mathrm{x}=$ 89 to $92, w=10$. Ventral hamuli bulky, with measurements: $a=62$ to $65, b=58$ to $60, c=3$ to $4, d=$ 17 to $18, \mathrm{e}=24$ to 26 . Dorsal transverse bar arcuate with processes nearly rounded off but forming single terminal cavity, with measurements: $x=90$ to $95, \mathrm{w}=$ 12. Dorsal hamuli with fracture between base and blade, with measurements: $\mathrm{a}=66$ to $68, \mathrm{~b}=45$ to $49, \mathrm{c}=$ rounded off, $d=23, e=21$ to 24 . Pharynx spherical, 60 to 70 in diameter. Testis intercecal, subspherical, 230 long by 175 wide. Cirrus indistinctly bipartite, 105 to 115 long, with thick-lipped basal aperture 55 long by 20 wide opening parallel to longitudinal body axis, with short sclerotized vane making about one spiral; distal portion slightly twisted. Prostatic reservoir 68 long. Prostatic structures fingerlike, about length of cirrus and about $1 / 3$ cirrus width, numbering four pair, emptying into anterior half of saccular prostatic reservoir. Vagina dextral, 102 long by 32 wide, with length $32 \%$ of body width, with longitudinal striae on sclerified wall. Seminal receptacle with vaginal duct entering vagina near proximal $1 / 4$ of structure on ventral face.

Hosts: Lactophrys triqueter (Linnaeus) (type-host) and L. bicaudalis (Linnaeus).

Site: Gills.

Localities: Sainte Anne (type-locality) and Sainte Rose, Guadeloupe.

Specimens deposited: Holotype, MNHNP No. TJ 61, paratype No. TJ 62.

Etymology: The Latin glandulosum, meaning glandular, refers to the conspicuous prostatic structures.

\section{Remarks}

The wide-lipped base of the cirrus, fingerlike prostatic structures, and haptoral morphology all constitute diagnostic features for this species. Haliotrema pacificus from a chaetodontid in Baja 
California has hooks similar to those in $H$. glandulosum, but its cirrus does not have a thick base; we examined a paratype (USNM Helm. Coll. No. 70975) and could not delineate the prostate.

Perhaps the prostatic structures in $H$. glandulosum are ducts or accessory vesicles rather than glands and are swollen with material from indistinct glands. Zhukov (1980) illustrated glands plus similar nondescribed structures in $H$. auribaculum Zhukov, 1980.

\section{Haliotrema minutum sp. $\mathbf{n}$.} (Figs. 31-35)

\section{Description}

Based on three whole mounts. Body 210 to 280 long by 70 to 100 . Haptor with 14 marginal hooklets. Eyespots numbering two pair. Ventral transverse bar resembling bulky ox-yoke, with measurements: $x=44$ to $52, w=4$ to 5 . Ventral hamuli bulky, with short shaft directed anteriorly, with narrow blade, with measurements: $a=32$ to $34, b=26$ to $28, c=4$ to $5, d=$ 12 to $13, \mathrm{e}=8$ to 10 . Dorsal transverse bar nearly straight, with posterolateral process about three times longer than hemispherical anterior lobe, with measurements: $x=60$ to $62, w=10$. Dorsal hamuli with elongated upturned guard and rounded shaft, with measurements: $a=31$ to $35, b=32$ to $34, c=4, d=$ 5 to $6, \mathrm{e}=10$ to 12 . Pharynx 20 to 25 long by 10 to 18 wide. Testis 50 long by 35 wide. Cirrus cone-shaped, arched distally, indistinctly bipartite, without sclerotized vane, 30 to 33 long, with opening 8 in diameter not parallel to longitudinal axis of body. Prostatic reservoir narrow and indistinct, ventral to cirrus. Prostatic glands relatively large, numbering 10 , with eight in arch and two internal to arch. Vagina dextral, sclerified with wide internal striae, 25 to 32 long by 11 wide, with length $30 \%$ of body width. Seminal receptacle elongate, attached directly to proximal end of vagina without distinct vaginal duct.

Type-host: Acanthostracion polygonius Poey.

Site: Gills.

Type-locality: Sainte Anne, Guadeloupe.

Specimens deposited: Holotype, MNHNP No. TJ 59, paratype No. TJ 60.

Etymology: The Latin minutum refers to the small size of the worm.

\section{Remarks}

The combination of elongated, J-shaped hamuli with massive bases, an ox-yoke-like ventral transverse bar, and a small body distinguish this species from all other species of Haliotrema. Assuming the species can grow larger without altering its vaginal-seminal receptacle relationship and the size and arrangement of its prostatic reservoir, these are also diagnostic characteristics. However, they have not been described critically for all members of the complex of species.
Haliotrema brevis from Zanclus canescens in the southwestern Pacific Ocean is similar to $H$. $m i$ nutum in size, shape of hamuli, and hook-shaped cirrus, but differs by having a membrane enclosing the arch of the cirrus, a narrow vagina, and transverse bars 34 to $41 \mu \mathrm{m}$ rather than 44 to 52 and 60 to $62 \mu \mathrm{m}$ long.

\section{DISCUSSION}

Johnston and Tiegs (1922) erected Haliotrema for $H$. australe Johnston and Tiegs, 1922 from the mullid Pseudupeneus signatus (Günther) (as Upeneus s.) in Moreton Bay, S.E. Queensland, Australia. They characterized the genus by having species with a haptor armed with a dorsal and ventral pair of hamuli, each joined by a transverse bar; eyespots lacking (although what appears to be two pair are illustrated in their Pl. XI, Fig. 13); intestinal ceca ending blindly; and vas deferens not looping around the left cecum. Since then, Yamaguti (1963: 65) examined the holotype and found the vas deferens to loop around the left cecum which he assumed joined the right one posteriorly, characteristics that Young (1968) used as the basis for his review of the genus. Mizelle and Price (1964), who presented a key to the ancyrocephalines, simultaneously assumed the original description was correct without examining the type-material, and therefore erected Parahaliotrema for species with eyespots, united ceca, and a dextral rather than dextroventral vagina. Later, Bychowsky and Nagibina (1970a), without mentioning Parahaliotrema, which Yamaguti (1968: 65) had considered a synonym of Haliotrema and we discussed earlier in this paper, presented data on specimens from Parupeneus indicus (Shaw) in the South China Sea that they considered conspecific with $H$. australe. The specimens had the looped vas deferens, posteriorly united ceca, and eyespots. Also, Paperna (1972a) reported as $H$. australe specimens from four mullids and a gerrid in the Gulf of Aqaba. He provided an illustration showing joined ceca and a looping vas deferens; however, no eyespots were shown and the vagina opened sinistrally.

Accepting the possibility of $H$. australe having ceca ending blindly and vas deferens not looping around the left cecum would necessitate transferring all but that species into Parahaliotrema, unless the group can be split further. That would be necessary if Yamaguti (1963) incorrectly interpreted the holotype, and specimens reported 
by Bychowsky and Nagibina (1970a) and by $\mathrm{Pa}-$ perna (1972a) were misidentified or misdescribed. Then $H$. australe would not be the only species in Haliotrema because our examination of holotypes of Ancyrocephalus parupenei Yamaguti, 1968 (UNSM Helm. Coll. No. 63605) from mullids and $A$. pauu Yamaguti, 1968 (USNM Helm. Coll. No. 63606) from holocentrids reveal that they belong in the same genus. Other species also probably belong in that genus. In fact, most ancyrocephalines described before 1960 require reexamination for structures other than hooks and hamuli as do many, such as Pseudohaliotrematoides bengalensis Gupta and Khanna, 1974, described after that period. Bychowsky and Nagibina (1970b) described additional material of Ancyrocephalus paradoxus Creplin, 1839, the type-species of the genus, and included only two species. In those, the ceca are not united, the vas deferens loops around the left cecum, and the vagina opens sinistrally. Consequently, whether $A$. parupenei and A. pau belong in Haliotrema (in the sense originally described), in a new genus, or in an available genus necessitates looking at material from Pseudupeneus signatus in Moreton Bay and at material of all species placed in Ancyrocephalus Creplin, 1839 and closely-related genera, as well as investigating all available generic names. In any event, members of at least two related genera infect mullids.

Numerous species are presently placed in $\mathrm{Hal}$ iotrema. Young (1968) recognized 35 in six main groups. To these Yamaguti (1968) added another 35, Bychowsky and Nagibina (1970a) added seven, Zhukov $(1976,1980)$ added 18, and more exist such as the three by Euzet and Vala (1977), five by Paperna (1972a, b), one by Obodnikova (1976), and one by Machida and Araki (1977). Also, Mizelle and Kritsky (1969) established six new species that we transferred from Parahaliotrema in the present paper. Presumably, more species exist and some names are junior synonyms; the genus needs critical review.

\section{ACKNOWLEDGMENTS}

We thank J. Ralph Lichtenfels for loan of specimens from the U.S. National Museum Helminthological Collection. C. E. Dawson allowed us to collect specimens of $H$. lactophrys from fishes in the Gulf Coast Research Laboratory Museum.

\section{LITERATURE CITED}

ByChowsKy, B. E., AND L. F. NAGiBinA. 1970a. [On the new and little known species of the genus $\mathrm{Hal}$ - iotrema Johnston and Tiegs, 1922 (Monogenoides)]. Zool. Zhurn. 49: 1789-1801 (in Russian). , AND 1 . 1970b. [Contribution to the revision of the genus Ancyrocephalus Creplin, 1839 (Dactylogyridae, Ancyrocephalinae)]. Parazitologyia 4: 193-200 (in Russian).

Euzet, L., AND J. C. Vala. 1977. Monogenes parasites de Mullidae (Teleostei) des Cotes de la Guadeloupe. Univ. Nat. Auton. de Mexico, Exc. Parasitol. en Mem. del Dr. Ed. Caballero y C. Publ. Espec. 4: 35-44.

HaRgIS, W. J., JR. 1955. Monogenetic trematodes of Gulf of Mexico fishes. Part II. The superfamily Gyrodactyloidea. (continued). J. Parasitol. 41: 185193.

Johnston, T. H., AND D. W. Tiegs. 1922. New gyrodactyloid trematodes from Australian fishes, together with the reclassification of the superfamily Gyrodactyloidea. Proc. Linn. Soc. N.S.W. 47: 83-131.

Lebedev, B. I. 1978. Some aspects of monogenean existence. Folia Parasitol. (Praha) 25: 131-136.

MacCallum, G. A. 1915. Some new species of ectoparasitic trematodes. Zoologica 1: 395-410.

Machida, M., AND J. ARAKI. 1977. Monogenetic and digenetic trematodes of the sweeper, Pempheris xanthoptera. Bull. Nat. Sci. Mus., Ser. A (Zool.) 3: $1-7$.

Mizelle, J. D., AND D. C. Kritsky. 1969. Studies on monogenetic trematodes. XL. New species from marine and freshwater fishes. Am. Midl. Nat. 82: 417-428.

- AND C. E. Price. 1964. Studies on monogenetic trematodes. XXV. Six new species of Ancyrocephalinae from the gills of Zanclus canescens (Linnaeus) with a key to the genera of Ancyrocephalinae. J. Parasitol. 50: 81-89.

OBoDNikova, V. A. 1976. A new representative of the genus Haliotrema (Dactylogyridae, Ancyrocephalinae) from Hapalogenys mucronatus. In Fauna, Systematics and Phylogeny of Monogenoidea. Proc. Inst. Biol. Ped. Far-East Sci. Cen., Acad. Sci. U.S.S.R. New Series 35(138): 89-91.

PAPERnA, I. 1972a. Monogenea from Red Sea fishes. II. Monogenea of Mullidae. Proc. Helminthol. Soc. Wash. 39: 39-45.

- 1972b. Monogenea of Red Sea fishes. III. Dactylogyridae from littoral and reef fishes. J. Helminthol. 46: 47-62.

Price, E. W. 1937. North American monogenetic trematodes. I. The superfamily Gyrodactyloidea. J. Wash. Acad. Sci. 27: 114-130, 146-164.

Randall, J. E. 1968. Caribbean Reef Fishes. T.F.H. Publications, Inc., Neptune City, New Jersey, $318 \mathrm{p}$.

Yamaguti, S. 1963. Systema Helminthum. IV. Monogenea and Aspidocotylea. Interscience Publishers, New York, 699 p.

1968. Monogenetic Trematodes of Hawaiian Fishes. University of Hawaii Press, Honolulu, $287 \mathrm{p}$.

Young, P. C. 1968. Ten new species of Haliotrema (Monogenoidea: Dactylogyridae) from Australian fish and a revision of the genus. J. Zool. Lond. 154: 41-75. 
Zнuкоv, E. V. 1976. New monogenean species of the genus Haliotrema Johnston and Tiegs, 1922, from the Gulf of Mexico fishes of the fam. Lutianidae. In Fauna, systematics and phylogeny of Monogenoidea. Proc. Inst. Biol. Ped. Far-East Sci. Cen., Acad. Sci. U.S.S.R. New Series 35(138): 33 47.
1980. Monogenea of the genus Haliotrema Johnston et Tiegs, 1922 from the gills of fishes fam. Holocentridae and fam. Acanthuridae of the Gulf of Mexico. Parazitologiya (Leningr.) 29: 4152. 